\title{
Household Costs Associated With Seeking Malaria Treatment During Pregnancy: Evidence From Burkina Faso and The Gambia
}

\section{Laetitia Duval}

Universite Paris 2 Pantheon-Assas Centre de Recherches en Economie et Droit

\section{Elisa Sicuri}

Imperial College London School of Public Health

\section{Susana Scott}

London School of Hygiene and Tropical Medicine

\section{Maminata Traoré}

Institut de Recherche en Sciences de la Santé - Clinical Research Unit of Nanoro

\section{Bunja Daabo}

London School of Hygiene and Tropical Medicine Population Studies Group

Halidou Tinto

6Institut de Recherche en Sciences de la Santé - Clinical Research Unit of Nanoro

\section{Koen Peeters Grietens}

Medical Anthropology Unit, Department of Public Health, Institute of Tropical Medicine

\section{Umberto d'Alessando}

Medical Research Council Unit The Gambia at London School of Tropical Medicine and Hygiene

\section{Henk Schallig}

Academic Medical Centre, Department of Medical Microbiology, Parasitology Unit, Amsterdam

\section{Petra Mens}

Academic Medical Centre, Department of Medical Microbiology, Parasitology Unit, Amsterdam

Lesong Conteh ( $\square$ I.conteh@lse.ac.uk)

London School of Economics and Political Science https://orcid.org/0000-0002-0719-3672

\section{Research}

Keywords: Malaria, pregnancy, cost, intermittent preventive therapy in pregnancy, Sub-Saharan Africa, Burkina Faso, Gambia

Posted Date: July 7th, 2020

DOI: https://doi.org/10.21203/rs.3.rs-40161/v1 
License: (c) (i) This work is licensed under a Creative Commons Attribution 4.0 International License. Read Full License 


\section{Abstract}

Background: Malaria in pregnancy remains a major health threat in sub-Saharan Africa to both expectant mothers and their unborn children. To date, there have been very few studies focused on the costs associated with seeking treatment for malaria during pregnancy. Methods. A cross-sectional survey was undertaken in Burkina Faso and The Gambia to estimate the direct (medical and non-medical) and indirect costs associated with outpatient consultations (OP) and inpatient admissions (IP). In total, 220 pregnant women in Burkina Faso and 263 pregnant women in The Gambia were interviewed about their treatment seeking decisions, expenditure, time use and financial support associated with each malaria episode . Results : In Burkina Faso 6.7\% sought treatment elsewhere before their OP visits, and 32.9\% before their IP visits. This compares to $1.3 \%$ for OP and $24.1 \%$ for IP in The Gambia. Once at the facility, the average direct costs (out of pocket) were 3.91US\$ for an OP visit and 15.38US\$ of an IP visit in Burkina Faso, and 2.75US\$ for an OP visit and 9.19US\$ for an IP visit in The Gambia. Inpatient direct costs were driven by drug costs (9.27US\$) and transportation costs (2.72US\$) in Burkina Faso and drug costs (3.44 US\$) and food costs (3.44 US\$) in The Gambia. Indirect costs of IP visits, valued as the opportunity cost of time lost due to the illness, were estimated at 11.85US\$ in Burkina Faso and 4.07US\$ in The Gambia. The difference across the two countries was mainly due to the longer time of hospitalization in Burkina Faso compared to The Gambia. In The Gambia, the vast majority of pregnant women reported receiving financial support from family members living abroad, most commonly siblings (65\%). Conclusions: To reach successful global malaria control, there is an urgent need to understand the barriers pregnant women face when seeking prevention and treatment for malaria at health facilities. Our findings suggest that direct and indirect costs, both medical and non-medical, are likely to affect access to health care.

\section{Background}

Malaria in pregnancy (MiP) is a major public health problem in sub-Saharan Africa (SSA). It also places an economic toll on individuals and nation states [1]. Pregnant women are at higher risk of malaria than other adults, leading to potentially adverse outcomes for their fetus, newborn child and themselves [2-5]. In 2018, prevalence of exposure to malaria infection in pregnancy was highest in the West African subregion and Central Africa (each with 35\%)[6]. The World Health Organization advocates prompt and effective management of clinical cases, long-lasting insecticidal nets (LLIN) and intermittent preventive treatment during pregnancy (IPTp). In all areas with moderate to high malaria transmission in Africa, a full therapeutic course of the antimalarial sulfadoxine-pyrimethamine (IPTp-SP) should be systematically given to pregnant women at each routine antenatal visit as far as these are at least one month apart and regardless of infection status $[7,8]$. Burkina Faso is one of only two African countries (the other one Tanzania) estimated to have more than half of pregnant women receiving three doses of IPTp in 2018 [6]. The success of IPTp delivery depends partly on access to, and use of, antenatal care by pregnant women. In 2016 about $26 \%$ of women did not attend ANC facilities during their pregnancy [9]. It is essential, therefore, to understand barriers to accessing facility based care if both IPTp coverage and rates of pregnant women receiving prompt and effective treatment are to increase. A range of geographic, 
economic, social and cultural factors contribute to the low use of antenatal clinics. These factors include, among others, distance and poor road infrastructure, low level of education, poverty, limited access to information or traditional values $[10,11]$. At the health facility level, confusion about timing of IPTp and difficult assessment of the gestational age have also been identified as obstacles [12,13]. Costs, both direct and indirect, have been shown to be an important barrier to pregnant women's use of health facilities, both for routine antenatal visits and to seek treatment more generally.

Costing studies associated with MiP are largely in the form of economic evaluations reporting either the actual or projected costs and cost-effectiveness of preventive interventions such as IPTp and LLIN [1418]. A few evaluate costs from the provider $[14,17,19,20]$ and/or user perspectives $[1,17,20-23]$. The aim of this study was to estimate the costs of malaria episodes incurred by pregnant women in Burkina Faso and The Gambia using primary, individual-level data collected after an outpatient consultation or at discharge after hospitalization. While we acknowledge that the costs of preventing and treating MiP are largely borne by the health care providers of these countries, pregnant women are likely to incur costs that can prohibit accessing prompt and effective health care. To our knowledge, these are the first published adult treatment seeking cost estimates for malaria in either Burkina Faso or The Gambia.

\section{Methods}

\section{Study Settings and Populations}

The study was part of a multi-centre (Benin, Burkina Faso and The Gambia) cluster-randomized controlled trial evaluating the effect of adding, between IPTp-SP given at antenatal visits, screening and treatment of pregnant women by Village Health Workers[24]. A cross-sectional study was designed to assess the direct and indirect costs associated with malaria from the pregnant women's perspective in all three countries. However, Benin was excluded because the low number of cost questionnaires collected precluded any meaningful analysis. The study was carried out between August 2014 and December 2015.

In The Gambia, the study was conducted in the eastern part of the country on the southern bank of the Upper River Region, around the Basse Health District. Although malaria in The Gambia has declined significantly over the last 10-15 years, there is still moderate and highly seasonal (July-December) transmission in its eastern region. In The Gambia, pregnant women confirmed to be Gambian nationals are not expected to pay for any fee for hospitalization or outpatient visits. Women crossing the border from Senegal are charged consultation fees. In Burkina Faso, the study was conducted in the Centre-West of the country, in the Nanoro Health District. Malaria transmission is high and extremely seasonal (JuneDecember)[24]. In Burkina Faso, the prevention tools (IPTp-SP and LLIN) are given free of charge to pregnant women during the ANC visits. At the time of the trial, pregnant women were expected to pay for malaria treatment.

\section{Data Collection}


Prior to starting the COSMIC study, community sensitization and involvement of village leaders was carried out at each study site. For this specific costing, pregnant women were invited to participate in the study before leaving a health facility. Before the interview experienced data collectors explained in the local language the written information and consent forms to potential participants. This conversation outlined study goals, the topic and type of questions respondents could expect and highlighted their right to decline participation, to interrupt or withdraw from the questionnaire at any time.

For those agreeing to participate, structured questionnaires were administered. The questionnaires comprised of five sections: 1 . socio-demographic characteristics of the study participants such as age, level of education and receipt of money from anyone living abroad; 2 . transportation costs to the health facility; 3 . treatment seeking behavior and previous treatments for symptoms associated with the same malaria episode; 4 . direct costs of treatment which was complemented with data abstracted from the prescription orders; and 5. time lost because of the illness.

\section{Data Management \& Analysis}

All data were collected through standardized questionnaires, double entered into a specially designed database and verified. Analysis was conducted using Microsoft Excel and Stata software (version 14, College Station, Texas, USA). All questionnaires were labeled with the pregnant woman's unique identity number and date of collection, thus ensuring anonymity. Costs were reported in local currencies. Costs were then converted to US dollars using the average exchange rate across the time of the study, specifically August 2014- December 2015 (OANDA)[25]).

Costs were broken down into both direct and indirect costs. Direct costs (out-of-pocket expenses) were further broken down into medical (such as admission fees, drug charges, and laboratory fees), and nonmedical (such as transportation and food). Indirect costs reflected time lost because of the illness. Indirect costs were collected for inpatient visits only. They were calculated by multiplying reported time lost by the nominal value of the median monthly permanent income per capita of households in Burkina Faso and The Gambia, represented by country specific estimates by the International Labour Organisation $[21,23,26]$. We tested whether costs, both direct and indirect, for previous treatment sought were statistically different between Burkina Faso and The Gambia for both inpatients and outpatients. We applied the Wilcoxon-Mann-Whitney non-parametric test because of the skewed cost distribution.

\section{Results}

Three hundred fifty-five outpatients (150 in Burkina Faso and 155 in The Gambia) and 178 inpatients (70 in Burkina Faso and 108 in The Gambia) were interviewed (Table 1). 
Table 1

Descriptive characteristics of the respondents

\begin{tabular}{|c|c|c|c|c|}
\hline \multirow[t]{2}{*}{ Country } & \multicolumn{4}{|c|}{ Burkina Faso Gambia } \\
\hline & Out Patient & In Patient & Out Patient & In Patient \\
\hline Number of observations & 150 & 70 & 155 & 108 \\
\hline Age (years) & 23 & 24 & 27 & 27 \\
\hline \multirow[t]{2}{*}{ Average Number of children } & 1.43 & 1.47 & 1.75 & 1.75 \\
\hline & \multicolumn{4}{|l|}{ Percentages } \\
\hline Diagnostic: clinical malaria & 100.00 & 71.43 & 65.16 & 56.48 \\
\hline severe anemia & 0.00 & 15.71 & 34.86 & 38.89 \\
\hline Malaria \& severe anemia & 0.00 & 12.86 & 0.00 & 4.63 \\
\hline Education: none & 76.67 & 72.86 & 64.52 & 70.37 \\
\hline primary & 12.00 & 11.43 & 21.29 & 17.59 \\
\hline secondary & 10.67 & 14.29 & 13.55 & 12.04 \\
\hline Religion: catholic & 52.67 & 52.86 & 1.94 & 3.70 \\
\hline Islam & 32.67 & 35.71 & 97.42 & 96.30 \\
\hline traditional African religion & 14.00 & 11.43 & 0.65 & 0.00 \\
\hline none & 0.67 & 0.00 & 0.00 & 0.00 \\
\hline Ethnicity: mossi & 92.00 & 78.57 & 0.00 & 0.00 \\
\hline gourounsi & 4.67 & 8.57 & 0.00 & 0.00 \\
\hline peuhl & 2.67 & 11.43 & 0.00 & 0.00 \\
\hline mandinka & 0.00 & 0.00 & 29.68 & 40.74 \\
\hline fula & 0.00 & 0.00 & 37.42 & 26.85 \\
\hline serahuleh & 0.00 & 0.00 & 29.68 & 27.78 \\
\hline Marital status: married & 86.00 & 72.86 & 91.61 & 92.59 \\
\hline in relationship & 12.00 & 24.29 & 0.65 & 1.85 \\
\hline single & 1.33 & 2.86 & 6.45 & 5.56 \\
\hline separated & 0.67 & 0.00 & 1.29 & 0.00 \\
\hline Activity: housewife & 29.33 & 41.43 & 15.48 & 11.21 \\
\hline farmer & 54.67 & 35.71 & 54.19 & 65.42 \\
\hline
\end{tabular}




\begin{tabular}{|lllll|}
\hline Country & \multicolumn{3}{l}{ Burkina Faso Gambia } \\
\cline { 2 - 5 } & Out Patient & In Patient & Out Patient & In Patient \\
\hline market trader & 6.00 & 8.57 & 5.81 & 3.74 \\
\hline no occupation & 6.00 & 11.43 & 9.03 & 5.61 \\
\hline others & 4.00 & 2.86 & 15.49 & 14.02 \\
\hline Partner's activity: farmer & 68.00 & 57.14 & 66.90 & 81.00 \\
\hline market trader & 8.67 & 5.71 & 11.97 & 6.00 \\
\hline civil servant & 2.67 & 2.86 & 13.38 & 8.00 \\
\hline no occupation & 0.00 & 1.43 & 0.70 & 0.00 \\
\hline others & 20.66 & 32.86 & 7.05 & 5.00 \\
\hline
\end{tabular}

Outpatient Characteristics

Pregnant women were younger and had on average less children in Burkina Faso than in The Gambia. In addition, there was a higher proportion of women with no formal education in Burkina Faso (76.6\%) than in The Gambia (64.5\%), with only $10.6 \%$ of women having completed secondary education in Burkina Faso and $13.5 \%$ in The Gambia. In both countries, the main activity was farming, for the women $(54.6 \%$ in Burkina Faso and $54.1 \%$ in The Gambia) and their partners $(68.0 \%$ in Burkina Faso and $66.9 \%$ in The Gambia). About half (52.7\%) of the women in Burkina Faso were Catholics while most (97.4\%) Gambian women were Muslims.

\section{Inpatient Characteristics}

Inpatient characteristics were similar to outpatient ones. Women in The Gambia were older (27.02 years) and had a higher number of children (1.75) than those in Burkina Faso (23.87 years and 1.47). Similarly, most women were farmers and had no formal education.

\section{Total Costs}

\section{Outpatient Visit Costs}

Table 2 reports the outpatient visit costs broken down by all cost centres. Medical costs including lab and other fees and drug costs were significantly lower in The Gambia (0.57US\$) than in Burkina Faso (3.57US\$). The outpatients in both countries did not report cost for food. For outpatients, direct costs were statistically different between the two countries (Pvalue $=0.00)$. 
Table 2

Unit costs of inpatient and outpatient visits (US\$)

\section{Country}

The Gambia

$\begin{array}{llll}\text { Out } & \text { In Patient } & \begin{array}{l}\text { Out } \\ \text { Patient }\end{array} & \text { In Patient } \\ \text { Patient } & & \end{array}$

\section{Previous treatment seeking cost}

Total median direct cost of previous treatment

$\begin{array}{llll}2.04 & 0.34 & 0.86 & 1.72 \\ (1.02 ; & (0 ; 4.59) & (0.57 ; 1.14) & (1.14 ; 3.44) \\ 2.72) & & & \end{array}$

\section{Direct costs}

Median cost lab and other test fees

0.17

1.53

0.80

0.57

$(0 ; 0.34)$

$(0 ; 5.27)$

$(0.57 ; 3.44)$

$(0.57 ; 1.14)$

Median cost drugs

3.4

9.27

0

3.44

(2.55; 4.08)

$(7.14 ; 13.00) \quad(0 ; 1.83)$

$(2.75 ; 4.02)$

0

2.72

0

2.06

Median cost transportation

$(0 ; 1.7)$

$(0 ; 5.44)$

$(0 ; 2.29)$

$(0 ; 2.75)$

Median cost food

NA

2.04

NA

3.44

$(1.36 ; 3.4)$

$(2.75 ; 3.44)$

Total median direct costs

\subsection{1}

15.38

0.57

9.19

(2.93;

5.61)

$(10.54 ; 20.31)$

$(0.57 ; 3.90)$

(7.12;11.03)

\section{Indirect costs}

Median value of time lost because of the NA illness

11.85

NA

$(7.11 ; 16.59)$

$(4.07 ; 5.43)$

Interquartile Range in parenthesis

NA $=$ Not asked

Inpatient Visit Costs

Table 2 reports also the inpatient visit costs. Medical costs for inpatients were higher in Burkina Faso (10.80US\$) than in The Gambia (4.01US\$). Although, the cost of food was higher in The Gambia (3.44US\$) than in Burkina Faso (2.04US\$), direct costs were significantly higher in Burkina Faso (15.38 US\$) than in The Gambia (9.19US\$). Indirect costs, including the value of time lost because of the illness, were significantly higher (11.85US\$) in Burkina Faso than in The Gambia (4.07US\$), a difference 
explained by the longer average hospitalization in Burkina Faso (3.55 days) than in The Gambia (1.21 days).

\section{Treatment Seeking Behavior and Associated Costs prior to Facility Visit}

Table 3 reports the sample of outpatients and inpatients that sought care before the consultations or admissions to the formal health facilities. Pregnant women were asked about previous treatments sought for the symptoms associated with the same malaria episode. Seeking treatment for the current malaria episode before the OP visit was more common in Burkina Faso (6.7\%) than in The Gambia (1.3\%). Indeed, in The Gambia only two women (1 from home and 1 from a pharmacy) sought treatment before their OP visit while, in Burkina Faso, 3 women had treatment from home, 2 from pharmacies, and 5 from a hospital). The mean cost of this first treatment was 1.51US\$ in Burkina Faso and 0.86US\$ in The Gambia. Only outpatients in Burkina Faso $(\mathrm{N}=3)$ reported having sought treatment from a second place, whose cost was on 4.87US\$. 
Table 3

Frequency and costs of previous treatment(s) sought

\begin{tabular}{|c|c|c|c|c|c|c|c|c|}
\hline \multirow[t]{3}{*}{ Country } & \multicolumn{8}{|c|}{ Burkina Faso Gambia } \\
\hline & \multicolumn{2}{|c|}{ Out Patient } & \multicolumn{2}{|c|}{ In Patient } & \multicolumn{2}{|c|}{ Out Patient } & \multicolumn{2}{|c|}{ In Patient } \\
\hline & $\%$ & $N$ & $\%$ & $N$ & $\%$ & $N$ & $\%$ & $N$ \\
\hline Any treatment before & 6.67 & $10 / 150$ & 32.86 & $19 / 70$ & 1.30 & $2 / 155$ & 25.92 & $28 / 108$ \\
\hline \multicolumn{9}{|l|}{$\begin{array}{l}\text { First place treatment } \\
\text { sought }\end{array}$} \\
\hline home & 30.00 & 3 & 43.47 & 10 & 50.00 & 1 & 32.14 & 9 \\
\hline traditional healer & 0.00 & 0 & 4.34 & 1 & 0.00 & 0 & 10.71 & 3 \\
\hline market & 0.00 & 0 & 0.00 & 0 & 0.00 & 0 & 0.00 & 0 \\
\hline pharmacy & 20.00 & 2 & 17.39 & 4 & 50.00 & 1 & 35.71 & 10 \\
\hline hospital & 50.00 & 5 & 17.39 & 4 & 0.00 & 0 & 21.42 & 6 \\
\hline \multicolumn{9}{|l|}{$\begin{array}{l}\text { Second place treatment } \\
\text { sought }\end{array}$} \\
\hline home & 50.00 & 2 & 25.00 & 1 & 0.00 & 0 & 0.00 & 0 \\
\hline traditional healer & 25.00 & 1 & 0.00 & 0 & 0.00 & 0 & 0.00 & 0 \\
\hline market & 0.00 & 0 & 0.00 & 0 & 0.00 & 0 & 0.00 & 0 \\
\hline pharmacy & 0.00 & 0 & 0.00 & 0 & 0.00 & 0 & 100.0 & 1 \\
\hline \multirow[t]{2}{*}{ hospital } & 25.00 & 1 & 75.00 & 2 & 0.00 & 0 & 0.00 & 0 \\
\hline & USS & $N$ & USS & $N$ & USS & $N$ & USS & $N$ \\
\hline $\begin{array}{l}\text { Mean cost of first } \\
\text { treatment }\end{array}$ & 1.51 & 10 & 2.21 & 19 & 0.86 & 2 & 2.74 & 28 \\
\hline $\begin{array}{l}\text { Mean cost of second } \\
\text { treatment }\end{array}$ & 4.87 & 3 & 20.14 & 3 & 0.00 & 0 & 0.00 & 1 \\
\hline $\begin{array}{l}\text { Mean total cost } \\
\text { previous treatment }\end{array}$ & 2.97 & 10 & 4.27 & 19 & 0.86 & 2 & 2.74 & 28 \\
\hline
\end{tabular}

Before their IP visit, $32.9 \%$ and $25.9 \%$ of women sought treatment in Burkina Faso and The Gambia, respectively. Inpatients reported being ill on average 3.21 (range 1-20) days in Burkina Faso and 1.83 (range 1-4) days in The Gambia before being hospitalized. Treatment prior hospitalization was more common in Burkina Faso (43.47\%) than in The Gambia (32.14\%), with most treatment from home or from a pharmacy or hospital. The mean cost of the first treatment for IP was higher in The Gambia (2.74US\$) than in Burkina Faso (2.21US\$). 
The mean total cost for an OP consultation, including any previous treatment, was 2.97US\$ in Burkina Faso and 0.86US\$ in The Gambia. For hospitalization, the cost was 4.27US\$ in Burkina Faso and 2.74US\$ in The Gambia for an admission. For inpatients, costs for first treatment sought and total were statistically different between the two countries (Pvalue $=0.0023$ and Pvalue $=0.0241$, respectively). For outpatients, costs for first, second treatment sought and total were not statistically different between the two countries (Pvalue $=1.000$, Pvalue $=0.6547$ and Pvalue $=0.5163$, respectively) .

\section{Transportation to the Health Facility}

Table 4 reports transportation costs. They are considered as direct non-medical costs. In Burkina Faso, most outpatients travelled by bicycle (52.6\%) and motorbike (26.0\%) while in The Gambia about half $(51.61 \%)$ travelled by foot. The time taken to reach the health facility was similar in the two countries, around 24 minutes (range 2-90 minutes in Burkina Faso; range 1-60 minutes in The Gambia). The use of an ambulance for inpatients was slightly higher in Burkina Faso (5.71\%) than in The Gambia (3.85\%).

Table 4

Transportation to the health facility

\begin{tabular}{|c|c|c|c|c|c|c|c|c|}
\hline \multirow[t]{3}{*}{ Country } & \multicolumn{8}{|c|}{ Burkina Faso Gambia } \\
\hline & \multicolumn{2}{|c|}{ Out Patient } & \multicolumn{2}{|c|}{ In Patient } & \multicolumn{2}{|c|}{ Out Patient } & \multicolumn{2}{|c|}{ In Patient } \\
\hline & $\%$ & $N$ & $\%$ & $N$ & $\%$ & $N$ & $\%$ & $N$ \\
\hline Transport*: foot & 21.33 & 32 & 8.57 & 6 & 51.61 & 48 & 7.70 & 2 \\
\hline bicycle & 52.67 & 79 & 17.14 & 12 & 0.00 & 0 & 0.00 & 0 \\
\hline motorbike & 26.00 & 39 & 67.14 & 47 & 13.97 & 13 & 3.85 & 1 \\
\hline taxi-moto & 0.00 & 0 & 0.00 & 0 & 13.97 & 13 & 34.60 & 9 \\
\hline Car & 0.00 & 0 & 0.00 & 0 & 13.97 & 13 & 42.30 & 11 \\
\hline donkey & 0.00 & 0 & 0.00 & 0 & 6.45 & 6 & 7.70 & 2 \\
\hline \multirow[t]{2}{*}{ ambulance } & 0.00 & 0 & 5.71 & 4 & 0.00 & 0 & 3.85 & 1 \\
\hline & time & $N$ & time & $N$ & time & $N$ & time & $N$ \\
\hline $\begin{array}{l}\text { Time taken to reach the health facility } \\
\text { (minutes) }\end{array}$ & 24.70 & 150 & 34.77 & 70 & 24.15 & 155 & 36.33 & 108 \\
\hline
\end{tabular}

\section{Financial Support}

Table 5 reports additional information on financial support. In terms of health insurance, no pregnant woman in Burkina had a health insurance while there were a few women with health insurance in The Gambia. Almost all women in The Gambia reported household savings while in Burkina Faso the proportion was extremely low. In The Gambia, a large part of household savings consisted of remittances sent by family members living abroad, with most of them made by siblings to the household (around 
$65 \%)$. Remittances were also made by other members of the family (27\%). About half of the remittances sent to The Gambia came from Italy, followed by France (12.5\%), Germany (9.6\%), United States (6.7\%) and United Kingdom (0.9\%).

Table 5

Financial support

\begin{tabular}{|lllll|}
\hline Country & \multicolumn{3}{l}{ Burkina Faso Gambia } & \\
\cline { 2 - 4 } & Out Patient & In Patient & Out Patient & In Patient \\
\hline Number of observations & 150 & 70 & 155 & 108 \\
\hline Health insurance & Percentages & & & \\
\hline Savings in the household & 0.00 & 0.00 & 1.29 & 3.70 \\
\hline Receiving government support & 0.67 & 2.86 & 90.32 & 96.30 \\
\hline Money from abroad & 0.00 & 0.00 & 0.00 & 0.00 \\
\hline Remitter: husband & 4.67 & 1.43 & 87.74 & 96.30 \\
\hline brothers/sisters & 3.33 & 1.43 & 5.88 & 3.85 \\
\hline Children & 0.00 & 0.00 & 63.24 & 68.27 \\
\hline other family members & 0.00 & 0.00 & 1.47 & 0.00 \\
\hline Friends & 0.67 & 0.00 & 28.68 & 27.88 \\
\hline Country's remitter: Italy & 0.00 & 0.00 & 0.74 & 0.00 \\
\hline Germany & 0.00 & 0.00 & 38.24 & 57.69 \\
\hline France & 0.00 & 0.00 & 11.76 & 9.62 \\
\hline United States & 0.00 & 0.00 & 19.12 & 12.50 \\
\hline United Kingdom & 0.00 & 0.00 & 4.41 & 6.73 \\
\hline Ivory Coast & 0.00 & 0.00 & 8.82 & 0.96 \\
\hline
\end{tabular}

\section{Discussion}

A recent review of the status of MiP highlights three main economic issues. First, MiP accounts for a notable proportion of the total health-care budget; second, direct and indirect costs incurred by pregnant women for malaria prevention and treatment are high and; third, strategies to decrease costs incurred (e.g., vouchers, social marketing, and delivery through community approaches) are effective, but they need to be scaled up [5]. In this paper, we concentrate on the second issue given limited available information on treatment costs associated with MiP from the pregnant women's perspective. 
In Nigeria, the average cost of treating an episode of malaria during pregnancy was reported as US\$11.86 (direct medical cost) and US\$18.97 (direct nonmedical cost)[1]. These unit costs amounted to an estimated annual total cost for malaria treatment during pregnancy of US\$78.6 million (0.016\% of the Nigerian Gross Domestic Product). The study emphasized that treatment costs in Nigeria are largely funded by out-of-pocket payments, further strengthening the argument that IPTp coverage, if increased, helps protect pregnant women against the financial strain of seeking treatment.

Malaria treatment also poses a significant economic burden on pregnant women in our study, particularly in Burkina Faso. The direct cost of inpatient treatment for malaria in Burkina Faso was US\$15.38, the equivalent of $55 \%$ of the monthly female agricultural wage (estimated at US\$28.31 per month[26]). In The Gambia it equates to 19\% (using a monthly ILO estimated female agricultural wage of US\$49.35, compared to $\$ 9.19$ direct costs of inpatient care). In 2016, a few months after the end of our data collection, the government of Burkina Faso established a free health care policy for women. The benefit package covers a wide range of services including antenatal care, the prevention of anemia and malaria. Consultation fees, prescriptions fees, laboratory tests, hospitalization expenses and the expenses of ambulance transportation between health facilities are covered. Health facilities are paid prospectively according to a fee-for-service method with scheduled fees. A recent study showed that while the policy has provided effective financial protection, a significant proportion of women continue to pay for services and consumables that should be free of charge[27]. Even if there is no fee attached to ANC visits and IPTp, there are still costs associated with visiting fixed. Our findings echo a study published on the costs associated with malaria treatment among pregnant women in Colombia where transportation was a sizable part of outpatients' and inpatients' direct costs [20].

This is the first study to explore the frequency of remittances to households with pregnant women. While there appears little or no health insurance, in The Gambia most women receive remittance from family members living abroad, mainly from a few European countries (Italy, France, Germany) and the United States. Our findings support 2018 World Bank estimates which state The Gambia, at 12.5\%, was the second largest recipient of remittances as a proportion of its GDP in Sub-Saharan Africa. Personal remittances only accounted for 3.2\% of Burkina Faso's GDP[28]. SSA data show that remittance per capita improves various health outcomes[29, 30]. Further work is needed however, to determine if remittance is specifically associated with improved health outcomes for pregnant women and their newborns.

There are limitations to this study. The costs data were obtained from a cross-sectional survey. Ideally, a longitudinal data would allow us to estimate the economic burden of malaria over the course of the entire malaria season and/or individual pregnancies to better reflect the impact of multiple episodes. We were only able to capture the costs of malaria episodes from women who visited the health facilities included in the study. The costs in this study are associated with the immediate malaria infections in pregnant women and do not consider the long-term costs of treating the consequences of maternal infection on the infant. For instance, the consequences of low birth weight have been studied previously [31-33]. 
The study represented an opportunity for comparative analysis across different settings. Burkina Faso and The Gambia represent two different areas of transmission intensity: low (Gambia) versus high (Burkina Faso). However, the key messages are the same in these two contexts: (i) reaching pregnant women in rural areas is essential for malaria prevention and control and (ii) treatment costs associated with malaria episodes amongst this vulnerable group are high.

\section{Conclusions}

Malaria continues to remain a major public health problem and causes significant economic burden especially among pregnant women in West Africa. In view of the lack of information on the economics of malaria treatment in pregnancy, the study estimated the direct and indirect costs incurred by pregnant women due to malaria after an outpatient consultation or at discharge after admission in Burkina Faso and The Gambia. Our results revealed the high costs incurred by pregnant women in both countries. The costs incurred by pregnant women may have a large impact on the budgets of the households, with consequences on the allocation of their limited resources. Our findings also suggest that the role of remittance, particularly in The Gambia, needs further investigation with a focus on the effect it may have on accessing health care.

\section{Declarations}

\section{Ethics approval and consent to participate}

Ethical approvals where given by The Gambia Government/Medical Research Council Joint Ethics Committee (SCC1336), the Comité d'Ethique Institutionnel du Centre Muraz in Burkina Faso (A202013/CE-CM), the Comité National d'Ethique pour la Recherche en Santé in Benin (0126/MS /DC/SGM/DFR/CNERS/SA) and the Imperial College Joint Ethics Committee. Informed written consent was obtained from all participants.

\section{Consent for publication}

Not applicable

\section{Availability of data and material}

The datasets used and/or analysed during the current study are available from the corresponding author on reasonable request.

\section{Competing interests}

The authors declare that no competing interests exist. 


\section{Funding}

The research is funded by the European Union Seventh Framework Programme (FP7/2002-2016) under grant agreement $n^{\circ} 305662-$ COSMIC (Project: Community-based scheduled screening and treatment of malaria in pregnancy for improved maternal and infant health: a cluster-randomized trial 'COSMIC'). The funder had no role in study design, data collection and analysis, decision to publish, or preparation of the manuscript. We acknowledge joint funding from the UK Medical Research Council and Department for International Development. MR/R015600/1

\section{Authors' contributions}

LD and LC drafted and wrote the manuscript. LC and LD conceived and designed the study. LD,ES \& LC provided the statistical input to the study. HS, PM, HT and UdA designed the COSMIC cluster-randomized, controlled trial, on which this economic study was based. All authors read, commented on and approved the final manuscript.

\section{Acknowledgements}

We are grateful to the pregnant women who participated in the study. We would like to thank the project staff, community health workers, nurses, medical officers and the community members for their cooperation during the study.

\section{References}

1. Onyia VU, Ughasoro MD, Onwujekwe OE. The economic burden of malaria in pregnancy: a crosssectional study. J Matern Fetal Neonatal Med. 2020;33:92-5.

2. Steketee RW, Nahlen BL, Parise ME, Menendez C. The burden of malaria in pregnancy in malariaendemic areas. Am J Trop Med Hyg. 2001;64:28-35.

3. Desai M, ter Kuile FO, Nosten F, McGready R, Asamoa K, Brabin B, Newman RD. Epidemiology and burden of malaria in pregnancy. Lancet Infectious Diseases. 2007;7:93-104.

4. Bardaji A, Sigauque B, Sanz S, Maixenchs M, Ordi J, Aponte JJ, Mabunda S, Alonso PL, Menendez C. Impact of Malaria at the End of Pregnancy on Infant Mortality and Morbidity. J Infect Dis. 2011;203:691-9.

5. Rogerson SJ, Desai M, Mayor A, Sicuri E, Taylor SM, van Eijk AM. Burden, pathology, and costs of malaria in pregnancy: new developments for an old problem. Lancet Infect Dis. 2018;18:e107-18.

6. WHO. World Malaria Report 2019. In CC BY-NC-SA 30 IGO (Organization WH ed. Geneva2019.

7. WHO. World Malaria Report 2012. Geneva: World Health Organization; 2012.

8. WHO. Guidelines for the treatment of malaria. Geneva: World Health Organization; 2015. 
9. WHO. World Malaria Report 2016. Geneva: World Health Organization; 2016.

10. Magadi MA, Madise NJ, Rodrigues RN. Frequency and timing of antenatal care in Kenya: explaining the variations between women of different communities. Soc Sci Med. 2000;51:551-61.

11. Okonofua FE, Feyisetan BJ, Davies-Adetugbo A, Sanusi YO. Influence of socioeconomic factors on the treatment and prevention of malaria in pregnant and non-pregnant adolescent girls in Nigeria. $J$ Trop Med Hyg. 1992;95:309-15.

12. Hill J, Hoyt J, van Eijk AM, D'Mello-Guyett L, ter Kuile FO, Steketee R, Smith H, Webster J. Factors Affecting the Delivery, Access, and Use of Interventions to Prevent Malaria in Pregnancy in Sub-
Saharan Africa: A Systematic Review and Meta-Analysis. Plos Medicine 2013, 10.

13. Crawley J, Hill J, Yartey J, Robalo M, Serufilira A, Ba-Nguz A, Roman E, Palmer A, Asamoa K, Steketee R. From evidence to action? Challenges to policy change and programme delivery for malaria in pregnancy. Lancet Infect Dis. 2007;7:145-55.

14. Hansen KS, Ndyomugyenyi R, Magnussen P, Clarke SE. Cost-effectiveness analysis of three health interventions to prevent malaria in pregnancy in an area of low transmission in Uganda. Int Health. 2012:4:38-46.

15. Fernandes S, Sicuri E, Kayentao K, van Eijk AM, Hill J, Webster J, Were V, Akazili J, Madanitsa M, ter Kuile FO, Hanson K. Cost-effectiveness of two versus three or more doses of intermittent preventive treatment for malaria during pregnancy in sub-Saharan Africa: a modelling study of meta-analysis and cost data. Lancet Glob Health. 2015;3:e143-53.

16. Mbonye AK, Hansen KS, Bygbjerg IC, Magnussen P. Intermittent preventive treatment of malaria in pregnancy: the incremental cost-effectiveness of a new delivery system in Uganda. Trans R Soc Trop Med Hyg. 2008;102:685-93.

17. Sicuri E, Bardají A, Nhampossa T, Maixenchs M, Nhacolo A, Nhalungo D, Alonso PL, Menéndez C. Cost-effectiveness of intermittent preventive treatment of malaria in pregnancy in southern Mozambique. PLoS One. 2010;5:e13407.

18. Becker-Dreps SI, Biddle AK, Pettifor A, Musuamba G, Imbie DN, Meshnick S, Behets F. Costeffectiveness of adding bed net distribution for malaria prevention to antenatal services in Kinshasa, Democratic Republic of the Congo. Am J Trop Med Hyg. 2009;81:496-502.

19. Bôtto-Menezes C, Bardají A, Dos Santos Campos G, Fernandes S, Hanson K, Martínez-Espinosa FE, Menéndez C, Sicuri E. Costs Associated with Malaria in Pregnancy in the Brazilian Amazon, a Low Endemic Area Where Plasmodium vivax Predominates. PLoS Negl Trop Dis. 2016;10:e0004494-4.

20. Sicuri E, Bardají A, Sanz S, Alonso S, Fernandes S, Hanson K, Arevalo-Herrera M, Menéndez C. Patients' costs, socio-economic and health system aspects associated with malaria in pregnancy in an endemic area of Colombia. PLoS Negl Trop Dis. 2018;12:e0006431.

21. Botto-Menezes C, Bardaji A, Campos GD, Fernandes S, Hanson K, Martinez-Espinosa FE, Menendez C, Sicuri E. Costs Associated with Malaria in Pregnancy in the Brazilian Amazon, a Low Endemic Area Where Plasmodium vivax Predominates. Plos Neglected Tropical Diseases 2016, 10. 
22. Mulligan JA, Yukich J, Hanson K. Costs and effects of the Tanzanian national voucher scheme for insecticide-treated nets. Malar J. 2008;7:32.

23. Sicuri E, Fernandes S, Macete E, Gonzalez R, Mombo-Ngoma G, Massougbodgi A, Abdulla S, Kuwawenaruwa A, Katana A, Desai M, et al: Economic Evaluation of an Alternative Drug to Sulfadoxine-Pyrimethamine as Intermittent Preventive Treatment of Malaria in Pregnancy. Plos One 2015, 10.

24. COSMIC Consortium. Community-based Malaria Screening and Treatment for Pregnant Women Receiving Standard Intermittent Preventive Treatment With Sulfadoxine-Pyrimethamine: A Multicenter (The Gambia, Burkina Faso, and Benin) Cluster-randomized Controlled Trial. Clin Infect Dis. 2018;68:586-96.

25. OANDA. https://www.oanda.com/lang/fr/currency/converter/.

26. International Labour Organization. Mean nominal monthly earnings of employees by sex and economic activity - ILO modelled estimates. ILOSTAT database 2020, https://ilostat.ilo.org/data. .

27. Meda IB, Baguiya A, Ridde V, Ouédraogo HG, Dumont A, Kouanda S. Out-of-pocket payments in the context of a free maternal health care policy in Burkina Faso: a national cross-sectional survey. Health Economics Review. 2019;9:11.

28. The World Bank. World Bank Migration and Development Brief: Personal remittances. https://dataworldbankorg/indicator/BXTRFPWKRDTGDZS?locations=GM Accessed 12.05.2020.

29. Amega K. Remittances, education and health in Sub-Saharan Africa. Cogent Economics Finance. 2018;6:1516488.

30. Amakom U, Iheoma C. Impact of Migrant Remittances on Health and Education Outcomes in SubSaharan Africa. IOSR Journal of Humanities Social Science. 2014;19:33-44.

31. Sachs J, Malaney P. The economic and social burden of malaria. Nature. 2002;415:680-5.

32. Alderman $\mathrm{H}$, Behrman JR. Reducing the incidence of low birth weight in low-income countries has substantial economic benefits. World Bank Research Observer. 2006;21:25-48.

33. Sicuri E, Bardají A, Sigauque B, Maixenchs M, Nhacolo A, Nhalungo D, Macete E, Alonso PL, Menéndez C. Costs associated with low birth weight in a rural area of Southern Mozambique. PloS one. 2011;6:e28744-4. 